\title{
Methanolysis of 7-Acetoxy-4-Methylcoumarin Catalyzed by Cyclosophoraoses Isolated from Rhizobium meliloti
}

\author{
Heylin Park, ${ }^{\dagger}$ Lin-woo Kang ${ }^{\dagger}$ and Seunho Jung ${ }^{\ddagger}{ }^{+*}$ \\ - Department of Adwanced Technology Fusion, ${ }^{\ddagger}$ Department of Bioscience and Biotechnologvi \\ Bio Molectlar Informatics Center, Konkuk Lniversity, Seoul 1+3-701, Korea. E-mail: shingakonkuk ac.kr \\ Received October 17, 2007
}

Key Words : Catalytic carbohydrate. Cyclosophoraoses. Flavonoid. 7-Acetoxy-4-methylcoumarin. Methanolysis

Cyclosophoraoses (cyclic-( $1 \rightarrow 2)$ - $\beta$-D-glucan, collectively "Cys") are unique molecules that are synthesized by members of the family Rhizobiaceae as an intro- and extraoligosaccharide. ${ }^{1}$ In Agrobacterintm and Rhizobitum species. this molecule contains glucose residues linked solely by $\beta$ 1,2-glycosidic bonds, and the predoninant ring size distribution is between 17 and 27 glucose residues (Figure 1). Additionally, Cys may become modified with anionic substituents. ${ }^{1}$ The biosynthesis of $\mathrm{Cys}$ is osmotically regulated. with high levels synthesized during growth at low osmolarity. This osmotic regulation was first observed in Agrobaterinm numefociens cultures. and it was proposed that the Cys may function during hypo-osmotic adaptation. ${ }^{2}$ $\mathrm{Cys}$ is also involved in the initial stage of the root-nodule formation of the Rhizobinm species in nitrogen fixation. ${ }^{3,4}$ $\mathrm{Cys}$ is suspected to be involved in complexation with various plant flavonoids throughout the process of rootnodule formation. Several reports have shown that $\mathrm{Cys}$ has a good potential as a host molecule for various inclusion complexation technologies; for example. as a solubility enhancer of poorly soluble gnest molecules. ${ }^{6.8}$ a chiral nuclear magnetic resonance (NMR) solvating agent ${ }^{13}$ and a chiral additive in capillary electrophoresis (CE) ${ }^{\text {li }}$ Recently. a novel function of Cys as a catalyst for methanolysis reaction has been reported. ${ }^{11} \mathrm{Cys}$ enhanced the rates of the methanolysis reactions of both oxazolone compounds and phospholipids. Even if the exact three-dimensional structure of Cys is not clearly identified. NMR ${ }^{12}$ and conformational studies $^{12,13}$ suggest that $C y$ s has flexible backbone structures and narrower cavity sizes than expected. The characteristic scaffold induced by $\beta-(1 \rightarrow 2)$-glycosidic linkages of $\mathrm{Cys}$ would provide an appropriate space for the binding of substrates, thus affording the possibility of a cataly tic reaction. ${ }^{11}$

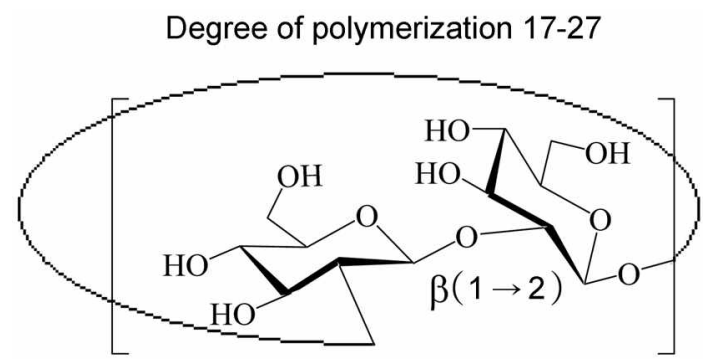

Figure 1. Chemical structure of Cys.
Herein, we report on the methanolysis of 7-acetosy-4methylcoumarin. one of the coumarin derivatives, catalyzed by Cys employed as a biological catalytic carbolydrate. Coumarin and its derivatives. flavonoids isolated from various plants. have been generally reported as antioxidants. ${ }^{1+}$ The reaction was monitored by ${ }^{~} \mathrm{H}$ NMR spectroscopy and high-performance liquid chromatograply (HPLC). The determination of the reaction intermediate formed on $\mathrm{Cys}$ during methanolysis of 7-acetoxy-4-methylcoumarin was also investigated by mass spectrometric analy sis.

First. we conducted isolation, purification. and structural analy ses of Cys as described previously. $\$ .15$ Through NMR spectroscopy and matrix-assisted laser desorption/ionizationtime of flight (MALDI-TOF) mass spectrometry. we confurmed that $\mathrm{Cys}$ is composed of unbranched cyclic $\beta(1 \rightarrow 2)$ D-glucans with various sizes from 17 to 27 in degree of polymerization (DP). Based on the MALDI-TOF mass

(A)

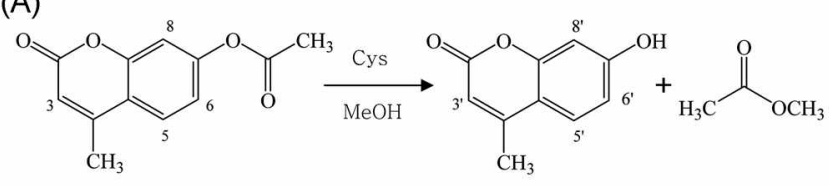

(B)

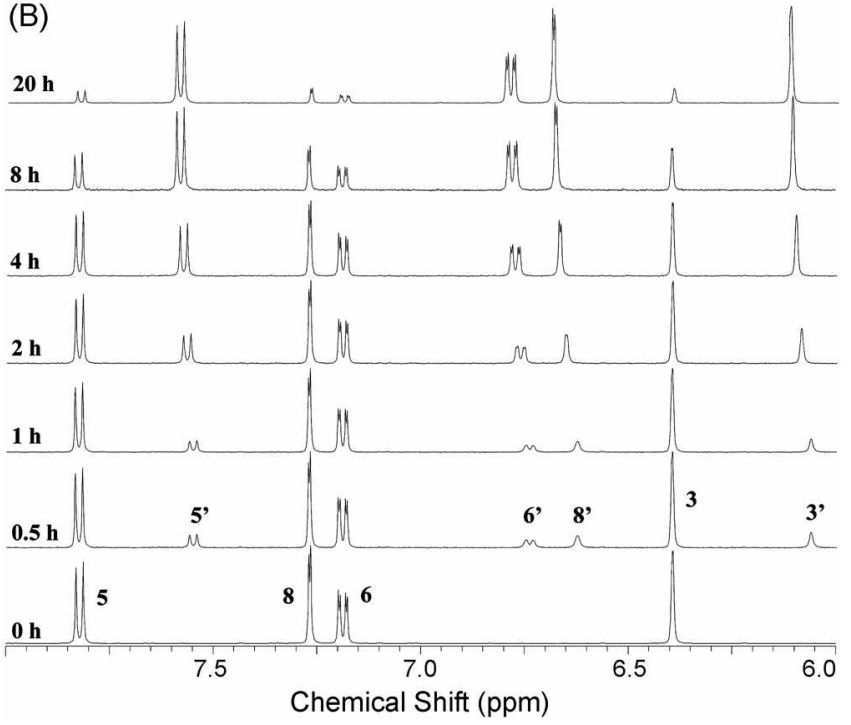

Figure 2. Scheme of methanolysis (A) and ${ }^{1} \mathrm{H} N \mathrm{NR}$ spectra (B) of 7-acetoxy-4-methy lcoumarin and cleaved coumarine derivative in presence of 0.1 equiv of $\mathrm{Cys}$ at different periods of time. 


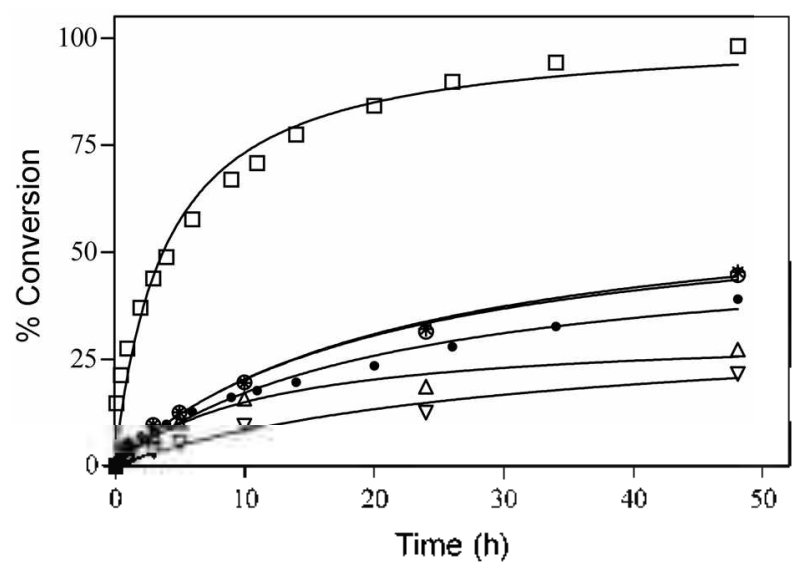

Figure 3. Time-course of methanolysis of 7-acetoxy-4-methylcoumarin in the absent and present of 0.1 equivalent $\mathrm{Cy}$ at $30^{\circ} \mathrm{C}$. The data were fitted to a single exponential to obtain $k_{\text {cat_cs: and }} k_{\text {(n) }}$. Svmbols: Cvs ( $匚$ ) , $4 \mathrm{mM}$ glucose (:), $88 \mathrm{mM}$ glucose (*), $4 \mathrm{mM}$ $\dot{\beta} \mathrm{CD}(\therefore)$, and $12 \mathrm{mM} \beta \mathrm{CD}(\tau)$, without catalyst $(\bullet)$.

spectrometry. the number-average molecular weight. $M_{n}$ of Cys was deternined as $3568.6^{8}$

Cys, one of the microbial carbohydrates, catalyzed the ester cleavage of 7-acetoxy-4-methy lcoumarin in methanol solvent as shown in Figure 2(A). Figure 2(B) shows the partial ${ }^{1} \mathrm{H}$ NMR spectra of 7-acetoxy-4-methylcounarin and cleaved coumarin derivative (product) in presence of 0.1 equiv of $\mathrm{Cys}$ at different periods of time. The proton peak of the exchanged methyl group of the product appeared at 30 $\mathrm{min}$ and increased with reaction time. $\mathrm{Cys}$-induced methanolysis of 7-acetoxy-4-methylcoumarin was also monitored by HPLC and then time-course curves were obtained where the reaction was enhanced about 11 .4-fold $\left(k_{\text {cat }} / k_{\text {ujcat }}\right)$ in the presence of 0.1 equiv of $\mathrm{Cys}$ in methanol at $30^{\circ} \mathrm{C}$ (Figure 3). Artificial enzymes generally have been reported to achieve rate enhancements between $10^{\mathrm{J}}$ and $10^{5}$. In this respect, this rate acceleration is modest compared to natural enzyme equivalent. ${ }^{16-18}$ In addition, methanolysis of 7-acetoxy-4. methylcoumarin was enhanced about 6-fold by succinoglycan acid polysaccharide from Rhizobium melitoti. ${ }^{19}$ We also investigated the methanolysis reaction by glucose $(4$ and $88 \mathrm{mM}$ ) and $\beta$-cyclodextrin $(\beta-\mathrm{CD} .4$ and $12 \mathrm{mM})$ to identify the effect of other typical carbohydrates. But the catalytic effects of glucose or $\beta$-CD were hardly detected when the glucose or $\beta$ - $\mathrm{CD}$ of same mole concentration or same amount (weight) with Cys were added (Figure 3). Besides. \% conversion of 7-acetoxy-4-methylcoumarin to product was decreased with concentration of $\beta$-CD. Although $\beta$-cyclodextrin $(\beta-C D)$ is known to be an interesting enzyme model. it was reported that $\beta$-CD did not accelerate. but rather retarded some reactions such as hydrolysis of aniline compounds depending on the substrate structure ${ }^{3 i}$ These results would be due to the fact that $\beta-C D$ inhibited the methanolysis of 7-acetoxy-4-nethy lcoumarin by undesirable interaction with the substrate.

The ester cleavage of the 7-acetoxy-4-methylcoumarin by a nucleophile can occur through a nucleophilic pathway with

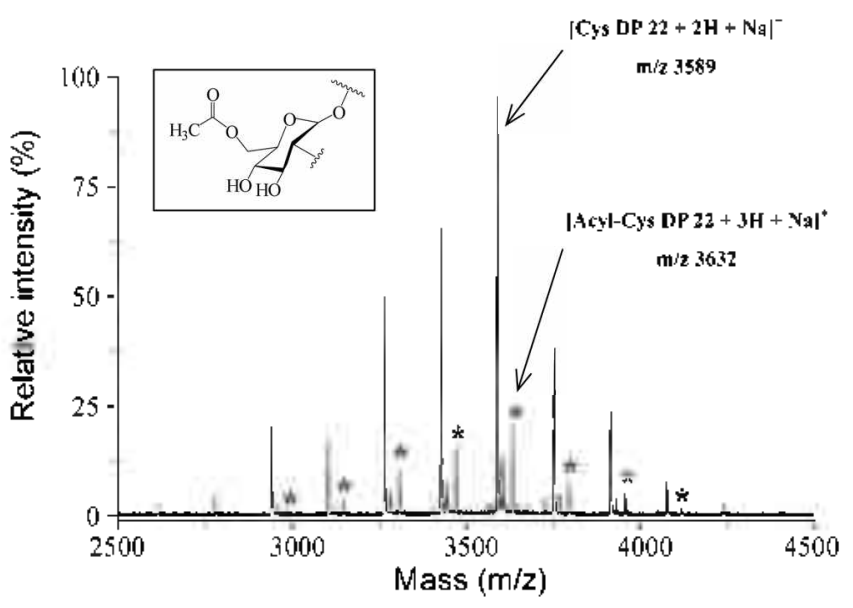

Figure 4. MALDI-TOF mass spectra of reaction mistures containing Cys and potential acyl intermediates formed on Cys (AcylCys). The each signal of at $\mathrm{m} / \angle 2778,2941,3103,3265,3427$, $3589,3752,3914,4076$, and 4238 corresponds to the DP of 17 to 26 Cys with cationized with one sodium, respectively. The asterisks indicate the sequential peaks, which were proposed to be Acyl-Cys containing acetyl $(\mathrm{m} / \angle 2820,2982,3145,3307,3470,3632,3794$, 3956 , and 4117). The chemical structure of a possible Acyl-Cys is shown in a square box:

the formation of intermediates that are produced from the release of the acetyl group of the substrate. MALDI-TOF mass spectrometric analysis of the reaction mixture was performed to assess whether intermediate of Cys was formed during reaction. In the mass spectrum of the reaction mixture of methanolysis of 7-acetosy-4-methylcoumarin by Cys. peaks at $\mathrm{m} / \mathrm{z} 2820,2982.3145 .3307,3470,3632$, 3794. 3956. and 4117 were newly detected (Figure 4). These molecular ions correspond to the results from $\mathrm{m} / \mathrm{z}$ shift of 42 , which could be attributed to the acyl moiety (acetyl) of 7-acetoxy-4-methylcounarin, as compared to the native $\mathrm{Cys}$ with DP 17 to 25 . Through the mass analysis. these sequential peaks were proposed to be acyl intemediates formed on Cy's (Figure 4)

In this study, we have described that Cys isolated from a soil microorganism. Rhizobium melloti. functioned as a catalytic carbohydrate in the methanolysis of 7-acetoxy 4methylcoumarin. a derivative of flavonoid. Cys enhanced the ester cleavage of 7-acetoxy-4-methylcoumarin about 11.4-fold ( $\left.k_{\text {cat }} / k_{\text {uncat }}\right)$ in methanol at $30^{\circ} \mathrm{C}$. In addition. possible acyl intermediates formed on $\mathrm{Cys}$ during reaction were revealed by MALDI-TOF mass spectrometric analysis. suggesting that Cys-catalyzed methanolysis likely proceed through a nucleoplilic pathway with an intemediate formation step. Although the exact reaction mechanism remains unclear. we assume that the catalytic methanolysis could be attributed to not only an appropriate space based on the characteristic scaffold induced by $\beta(1 \rightarrow 2)$-glycosidic linkages within Cys for the binding of substrates but also an attack of hydroxyl group of Cys as a nucleophile. This result and previous report of methanolysis catalyzed by Cys suggest that a microbial catalytic carbohydrate. Cys. has catalytic ability for transesterification of ester compounds 
through nucleophilic pathway in organic solvents and its ability is dependent on the structure of substrate. The study made it possible to advance further studies on catalytic functions of other nicrobial carbohydrates which are comparable to typical enzyme models. ${ }^{.33^{3}}$

\section{Experimental Sections}

Materials. All the chemicals containing 7-acetoxy-4methylcoumarin were purchased from the Signa Chemical Co. (St. Louis, MO, USA). D2O (99.9 atom \% D), CDCl (99.9 atom \% D), and DMSO- $d_{6}(99.9$ atom \% D) were purchased from Aldrich Chenical Co. (Milwaukee. WI. USA).

Preparation of cyclosophoraoses. Rhizobitm meliloti were cultured in a 5-L jar fermenter containing glutamic acid-mannitol-salts (GMS) medium to a late logarithmic phase at $30{ }^{\circ} \mathrm{C} .{ }^{11}$ Cells were harvested by centrifugation $\left(8,000 \mathrm{rpm}\right.$. at $\left.4{ }^{\circ} \mathrm{C}\right)$ and then extracted with $75 \%(\mathrm{v} / \mathrm{v})$ ethanol at $70{ }^{\circ} \mathrm{C}$ for $30 \mathrm{~min}$. After centrifugation. the supernatant was concentrated on a vacuum rotary evaporator. The concentrated sample was chronatographed on a Sephadex G-50 colunm $(3 \times 130 \mathrm{~cm})$ at a rate of $1 \mathrm{~mL} / \mathrm{min}$ and eluant fractions $(7 \mathrm{~mL})$ were assayed for carbohydrate by the phenol-sulfuric acid method. The fractions containing Cys were pooled, concentrated. and desalted using a Sephadex G-10 column $(2 \times 20 \mathrm{~cm})$. The desalted sample was then applied to a column $(2 \times 20 \mathrm{~cm})$ of DEAE-cellulose to separate neutral and anionic $\mathrm{Cys}$. After the neutral Cys were desalted using a Sephadex G-10 colunn $(2 \times 20$ $\mathrm{cm}$ ), they were also confirmed on thin layer chromatography (TLC, BuOH:EtOH:water $=5: 5: 4, \mathrm{v} / \mathrm{v}) .2$ NMR spectroscopy ${ }^{7,8}$ and MALDI-TOF mass spectrometry. ${ }^{\circ}$

General experimental procedures. NMR spectra were recorded in $\mathrm{D}_{2} \mathrm{O}, \mathrm{CD}_{3} \mathrm{Cl}$ or DMSO- $d_{6}$ with a Bruker $\mathrm{AMX}$ spectrometer (operated at $500 \mathrm{MHz}$ for $1 \mathrm{H} .125 \mathrm{MHz}$ for $13 \mathrm{C}$ ) at $25^{\circ} \mathrm{C}$. All NMR measurements were performed with $0.7 \mathrm{~mL}$ samples in $5 \mathrm{~mm}$ NMR tubes. Tetramethylsilane (TMS. Me $\mathrm{MS}_{4} \mathrm{Si}$ ) was used as an external reference, and chemical shifts were calibrated with an accuracy of $0.05 \mathrm{ppm}$. A Jupiter C18 column $(5 \mu \mathrm{M}, 250 \times 4.60 \mathrm{mum})$ was used for HPLC (Shimadzu. Japan) experiments. The analysis was carried out at $30^{\circ} \mathrm{C}$ and a flow rate of $1 \mathrm{~mL} / \mathrm{min}$ with the mobile phase (water:acetonitrile $=60: 40 . \mathrm{v} / \mathrm{v}$ ). Elution was monitored at $270 \mathrm{~nm}$. MALDI-TOF mass spectra were obtained with a MALDI-TOF mass spectrometer (VoyagerDETM STR Bio-Spectrometry. Applied Biosy'stems. Framingham. MA. USA) in the positive ion mode using 2.5dilydroxybenzoic acid (DHB) as the matrix. Approximately $0.5 \mu \mathrm{L}$ of the sample/matrix mixture was applied to the MALDI probe, and the solvent was removed by evaporation.

General procedure for the methanolysis by Cys. The reaction was carried out in $\mathrm{MeOH}(2 \mathrm{~mL})$ containing $40 \mathrm{mM}$ of 7-acetoxy-4-methylcoumarin at $30^{\circ} \mathrm{C}$ in the absence or presence of 0.1 equiv of $\mathrm{Cys}$. To identify the effect of other typical carbohydrates 4 or $88 \mathrm{mM}$ glucose and 4 or $12 \mathrm{mM}$ $\beta \mathrm{CD}$ were also tested. The glucose or $\beta \mathrm{CD}$ of same mole concentration or same amount (weight) with Cys was added. Aliquots were periodically withdrawn and analyzed by NMR spectroscopy or HPLC. The values of $k_{\text {cat_cys }}$ and $k_{\text {uncat }}$ were calculated by integration of the respective HPLC peaks were assigned to substrate and product. The data were fitted to a single exponential to obtain $k_{\text {cat } C \text { s }}$ and $k_{\text {uncat. }}$. To measure the possible acyl intermediates. 7-acetoxy-4-metlyylcoumarin $(70 \mathrm{mM})$ was dissolved in $1 \mathrm{~mL}$ of $\mathrm{MeOH}$, and Cys $(5 \mathrm{mg})$ was then added. At $l \mathrm{~h}$, the reaction mixture was completely evaporated at room temperature. and subjected to extraction after adding $\mathrm{lmL}$ of water and chloroform. respectively. The intermediates dissolved in the water layer were then analyzed by MALDI-TOF mass spectrometry

Acknowledgement. This research was supported by the Korea Research Foundation (KRF-2006-005-J03402). SJ expresses his thank to Konkuk University for the funancial support his sabbatical year. SDG

\section{References}

1. Breedveld, M. W. Miller. K. J. Aficrobiol Rev 1994. 58,145

2. Miller. K. J.; Kennedy, E. P.: Reinhold, V. N. Science 1986, 231.48

3. Andre. L.: Mazeau, K.: Taravel, F. R.: Tvaroska, I. Int. d. Macromol 1995. 17, 189

4. Spaink. H. P. Plam Mol. Biol 1992. 6.977

5. Morris. V. J.: Brownsey. G. T.: Chilvers. G. R.: Harris. J. E. Gunning. A. P.: Stevens. B. H. J. Food Hydrocoll. 1991. 5. 185.

6. Kwon. C.: Choi. Y.: Kim, N.: Yoo. J.: Yang. C.: Kim. H.: Jung. S J. hal Phenom 2000. 36, 55

7. Lee. S: Kwon. C: Choi, Y.: Seo. D:; Kim. H: Jung. S. $d$ Microbiol. Biotechnol 2001. 11. 463 .

8. Lee. S.: Sec. D.: Kim. H.: Tung. S. Carbohnd: Res. 2001. 33H. 119

9. Lee. S.: Tung. S. Carbolnd: Res. 2002. 337.1785

10. Lee. S.: Jung. S. Carbohly r Res. 2003. 338,1143

11. Lee. S.: Jung. S. Carbolydr: Res. 2004. 339, 461.

12. Mimura. M.: Kitamura, S: Gotoh. S.; Takeo. K.: Urakawa, H. Kajiwara. K. Carbohdr. Res 1996. 289. 25.

13. Choi. Y: Yanga. C.: Kim. H.: Jung. S. Carbohndr. Res. 2000.326. 227.

14. Konstantina, C. F.: Dimitra. J. H.: Konstantinos. E. L.: Demetrios. N. N. Cwr Pham Design 2004. 10. 3813

15. Lee. S.: Seo. D: Park. H.: Choi, Y; Jung, S. Anonie van Leetwenhoek 2003. 84. 201.

16. Ortega-Caballero. F.: Bjerre. J:: Laustsen. L. S.: Bols. M. J. Org Chent 2005. 70. 7217 .

17. Rousseau, C.: Nielsen. N.: Bols. M. Tetrahedron Lett. $2004,45$. 8709.

18. Ikeda, H.: Horimoto, Y.; Nakata. M: Ueno. A. Tetrahedron Lett. 2000. H. 6438

19. Kan1g. S.: Lee. S.: Kyung. S.: Jun1g. S. Bull. Korew Chem. Soe 2006. 27. 921

20. Palmer. D. R. J.: Buncel, E.: Thatcher, G. R. J. d. Org. Chem 1994. 59,5286

21. Djedani, F; Lin. S. Z; Perly, B.: Wouessidjewe, D. J. Pham. Sci. 1990. 79. 643

22. Bettinetti. G.: Melanii. F.: Mura. P.: Monnanni. R.: Giordano. F. J. Pham Sci. 1991. 80. 1162

23. Choi. Y. J.; Lee. J. H.: Cho, K. W.: Hwang, S. T.; Jeong, K. J.; Jung. S. H. Bull. Korean Chem. Soc. 2005. 26, 1203.

24. Ali. S. M.; Asmat. F; Koketsu, M. Bull. Korean Chem. Soc. 2006. 27. 1397. 